\title{
Psychological consequences of IVF fertilization - Review of research
}

\author{
Alicja Malina', Julie Ann Pooley² \\ 1 Instytut Psychologii, Wydział Pedagogiki i Psychologii, Uniwersytet Kazimierza Wielkiego \\ 2 School of Arts and Humanities, Edith Cowan University
}

Malina A, Pooley JA. Psychological consequences of IVF fertilization - Review of research. Ann Agric Environ Med. 2017 ; 24(4): 554-558. doi: $10.5604 / 12321966.1232085$

\begin{abstract}
Introduction and objective. Due to the reported efficacy of in vitro fertilization (IVF) this method of dealing with infertility is increasing being used. Experiencing IVF can be a source of psychological and emotional difficulties for couples trying to have a child. A systematic review was performed to discuss IVF as a psychological issue that impacts on the functioning of individuals, couples and families. Ebsco, Science Direct and PsycARTICLES databases were searched using the keywords: IVF fertilization, IVF psychology, infertility, and IVF consequences, using published peer reviewed articles from 2006 onwards. Studies in the English and Polish languages, peer reviewed and investigating general IVF and infertility psychological issues were included. Data was collected by the authors between June 2015-January 2016.

Brief description of the state of knowledge. Studies indicate that partners going through IVF may not have enough support from their closest social environments. It is argued that these unsupportive social interactions affect the well-being of couples, can hinder conception, and therefore are one of the reasons for attrition from IVF, the most effective assisted reproduction method.

Conclusions. There is a need to conduct studies on the effect of supportive social interactions for the functioning of couples undergoing IVF.
\end{abstract}

Key words

infertility, assisted reproductive techniques, in vitro, in vitro psychological consequences

\section{INTRODUCTION}

The percentage of infertile couples is constantly increasing. Worldwide, it is reported that 60-80 million couples are affected by fertility issues, with every fifth couple in Europe having problems with conceiving offspring $[1,2]$. There are many reasons for infertility. One contemporary issue identified is the delay in the onset of parenting roles past the optimal age of fertility, this being 20-24 years old. Current statistics show the average age of giving birth in Europe and the USA at over 30 years old $[3,4]$. In addition, modern stressors are possibly adding to the increase of infertility on the global level.

Infertility, while seen as a medical condition that prevents individuals from becoming parents, has also been shown to have potentially serious emotional and psychological consequences. It is a problem related to the anguish and frustration of not being able to conceive [5]. In the psychological literature, emotional problems arising from infertility have been described as a crisis $[6,7]$, where the stress connected with the inability to conceive may be compared to the stress connected with the loss of a close person [8]. Research reveals that as many as $48 \%$ of the people who are infertile, rate it as the worst experience of their life [9].

The beginning of infertility treatment is frequently a difficult decision for the couples as it is connected with the stress associated with the inability to conceive naturally and the giving up of control over their own bodies. The

Address for correspondence: Alicja Malina, Instytut Psychologii, Wydział Pedagogiki i Psychologii, Uniwersytet Kazimierza Wielkiego

E-mail: alamalina@gmail.com

Received: 28 June 2016; accepted: 20 September 2016; first published on February 2017 medical profession offers different types of infertility treatment methods: pharmacological, surgical and assisted reproductive techniques (ART) [10]. Assisted reproductive techniques (ART) include, among other methods, intrauterine insemination and in vitro fertilization (IVF). Due to the reported efficacy of IVF, this method of dealing with infertility is popular and increasing in use. The first child conceived through IVF was born in the United Kingdom in 1978. In 2010, $1 \%$ of all children born in the USA, around $2 \%$ in the UK and almost $4 \%$ in Denmark and Finland, were conceived through IVF [11]. Many infertile couples endure the distress of their situation for several years which gives rise to many psychosocial consequences (anxiety, depression, relationship issues, social isolation and feeling of guilt and inferiority) [12]. However, many of these couples end up using IVF as a method of choice in treating infertility. A consequence for couples choosing IVF is the increasing stress and consequences resulting from the IVF process itself [7, $9,13,14,15]$. Therefore, going through IVF can be a source of enormous psychological and emotional difficulties for couples trying to conceive a child $[5,16,17]$.

IVF treatment appears to be particularly emotionally difficult, and with this in mind, the focus of this review is discussing infertility as more than a medical issue of great interest to social scientists worldwide, as it impacts on the functioning of individuals, couples and families across the globe.

\section{OBJECTIVE}

The objective of this review is to discuss IVF as a psychological issue that impacts on the functioning of individuals, couples and families. In order to investigate this issue, published 
research carried out after 2006 were included in the search strategy. A systematic database search was used by key words: IVF fertilization, IVF psychology, infertility, IVF consequences. Using the snowball effect articles related to those primarily found were also reviewed. Data was collected by the authors between June 2015 - January 2016. Studies in the English and Polish languages, peer reviewed, that investigated general IVF and infertility psychological issues were included in the study.

State of knowledge - Psychological consequences of infertility. The first reaction to the diagnosis of infertility is usually one of disbelief or even denial. Couples tend to experience fear, sorrow, distrust and hostility in reaction to the diagnosis of infertility [5, 17]. Men and women going through infertility issues tend to feel guilty about not fulfilling their partner's needs and can suffer from mood deterioration [18]. Failures in conceiving a child are related to the increased level of anxiety and depression $[19,20]$, feelings of helplessness and worry [21]. Both partners also experience problems with self-esteem in the face of their infertility, which may also influence any further treatment $[22,23]$.

Studies indicate that emotional reactions to infertility by men and women are quite similar. Experiencing negative emotions connected with the inability to be a parent concerns women especially, for whom being a mother is an important aspect of their social role and their individual identity [24]. Research suggest that considerable change occur in the area of identity of childless women [25]. Women are also more prone to the negative consequences of the stress related to infertility, and their emotional reactions are more intensive [19]. Women, more often than males, feel uneasy and sad concerning their infertility. In addition, infertility appears to be more central to women's lives [26]. Men, in turn, identify their infertility with sexual disability which strongly influences their self-esteem [18]. Therefore, men tend to hide the information that the cause of infertility may be due to their own medical issues, and they are not eager to talk about their feelings connected with being unable to conceive a child [27]. Keeping the problem to themselves is probably the most prominent factor that differentiates men and women in the process of coping with infertility [21]. Overall, infertility is a more stressful experience for women than for men [26, 28 ], and comparing to infertile men, infertile women tend to score lower on measures of psychological adjustment [21].

For a couple that cannot naturally have children, regardless of the differences between men and women, infertility considerably influences the quality of the partners mutual relations [17]. Firstly, the couples appraisal of marriage and satisfaction with a shared life is lower $[22,29]$. The strong emotions related to infertility experienced by the couple have a negative influence on a number of aspects of the functioning of the couple, e.g. bond, communication and sexual adaptation. Research provides information that infertility leads to the feeling of guilt resulting from the inability to produce a child for their partner; hence, the bond between the individuals may be impacted. What is also commonly observed among infertile couples, is the effect on communication which makes their relationship difficult. Research indicates that the longer the infertility situation lasts, the more the partners experience their sorrow separately and silently [30]. The distance, isolation and difficulties in talking about issues related to infertility results in an increase in the tension between partners, leading to crises [31, 32]. The difficulty in conceiving also affects the quality of sexual intercourse. Undoubtedly, infertility is a factor which has a negative impact on the relationship between partners and the satisfaction with sexual life; however, it is uncertain how long the issues remain $[33,34]$.

Summing-up, research findings confirm the effects of infertility-related stress on both emotional and marital distress. However, infertility-related stress was found to have more impact on one's emotional distress than on marital satisfaction [29].

Effect of IVF treatment on couples. Although IVF is one of the most commonly used methods of ART, it is also well established that it is psychologically a very difficult process to go through. Research reports that significant transformations occur in the psyche of individuals undergoing IVF treatment [30].

The literature review reveals that just before starting IVF treatment, men and women score similar to normative samples in anxiety, self-esteem, mood and general psychological wellbeing, life satisfaction and depression [35]. This may be related to the high expectations towards IVF and a rationalization of the couples choice of using IVF. Therefore, while couples entering IVF treatment are generally well-adjusted, a number of studies suggest that immediately prior to starting IVF treatment the couple undergoing the procedure begin to experience emotional problems.

There is evidence throughout IVF studies that the procedure is reported by patients as moderately to very stressful, with the most stressful component being the waiting period related to hear the results of a successful or unsuccessful IVF attempt [36]. There is also evidence of other, more specific problems connected with undergoing IVF. Firstly, in the process of treating infertility, the satisfaction with a couple's relationship deteriorates, including satisfaction with the sexual life [37]. As couples only concentrate on the biological aspect of fertility and focus on the technical side of sexual intercourse, this results in the weakening of emotional bonds which leads to the loss of pleasure, and diminishes the spontaneity and desire [33].

Studies in the field of IVF treatment are concerned mainly with the female partner, indicating that women are more at risk for developing emotional problems during and after fertility treatment than their male partners [38]. There is consistent evidence that throughout all stages of an IVF cycle, women tend to experience greater negative psychological reactions to treatment, compared to men [5], which includes increased levels of anxiety among women undergoing IVF treatment [39]. It was also agreed that the negative outcomes of going through the IVF procedure may be long-lasting. In a 20-year follow-up study of women who had undergone IVF treatment, it was found that the women reported more depressive, obsessive-compulsive and somatization symptoms than the reference group [40].

There has been much concern expressed regarding the potential negative psychological consequences following an unsuccessful IVF attempt [17]. Eugster and Vingerhoets [5], in their review of the literature, found that frequently occurring responses after an unsuccessful IVF included tension, sadness, anger, and depression, as well as feelings of helplessness, loss, and guilt. In addition, although women appear to be at greater risk for negative psychological consequences of IVF than 
men, men also reported significant negative psychological response after a failed treatment cycle. Even successful IVF may be followed by some distress. Studies support the notion that IVF couples tend to experience more pregnancy-related anxiety than comparison groups of fertile individuals [41]. Studies also reveal that negative feelings related to infertility may continue to affect self-image for the IVF couples after pregnancy and childbirth were achieved [42].

Significance of IVF for the relationship with the child. In the medical environment it is increasingly reported that the long-term influence on the life and health of the child conceived via IVF is not known [43]. Carrying-out the analysis of the influence of the IVF method on the pregnancy and the development of a infant is difficult due to the small amount of research carried out. This results from the unwillingness of the parents to maintain contact with the clinic, and to reveal the way their child was conceived [44]. Parents are usually unlikely to take part in research after an IVF process has been undertaken.

There is some evidence that attachment to the foetus and the parent-infant relationship among IVF families are similar to comparison groups. Anxiety about the survival of the foetus and early parenting difficulties, appear to be higher and post-natal self-confidence lower for IVF parents. It is possible that in an IVF pregnancy, parenthood might be idealized and it could be more difficult to adjust and form a parental identity [45]. It is argued that the IVF procedure is a stressor which may influence early parental behavior, and therefore influence the psychosocial development of the child $[46,47]$. Mothers of children conceived via IVF, for example, are characterized by a higher level of protectiveness towards their children, and are regarded as warmer emotianally. Mothers also reveal a higher level of sensitivity towards their children than parents of children conceived naturally. Some studies indicate that the parents of children conceived through IVF reveal a higher estimation of the parenthood itself, which contributes to gaining higher satisfaction with the relations with the offspring [48]. This may be also why children conceived through IVF interact with their parents more easily $[46,47]$

Factors connected with the success of the procedure. Parenthood is regarded as an important and common role that is part of being treated as a valuable member of society. The level of social acceptance of infertility treatment methods differs, depending on age, level of education and income of respondents [49].

Negative attitudes towards childless marriages may increase the feeling of loss, shame, and intensify the emotional crisis connected with childlessness and have a negative influence on the marital relationships $[8,25]$. Reaction to the diagnosis of infertility is therefore related with social pressures and coping with the treatment, which also depends greatly on the support that the couple receives from their social network. Several studies have documented the relationship between support from social network members and positive adjustment among infertile individuals [50]. Literature suggests that support is important for the process of treatment and coping with such a difficult process as IVF treatment. A lack of social support negatively influences the general psychological condition of the couple, and contributes to the growth of depression, and hinders the process of coping [51]. Particularly important here are the relations with the closest relatives of the infertile couple: the partner, the family of origin and friends [27].

Unfortunately, studies indicate that IVF couples often lack support from social network members [52]. Although Polish general opinion about the in vitro is more positive today than it was several years ago, it has to be acknowledged that the assisted reproduction techniques are contrary to the preaching of the Catholic Church, which is an additional psychic burden and a major source of stress for many couples who decide to undergo IVF [53]. Given the social stigma associated with infertility and the secrecy that accompanies taking-up treatment, individuals with fertility problems do not often talk openly about their infertility, even with family members and friends [25]. Therefore, one's partner or spouse often becomes the main source of support [54]. About $70 \%$ of the women and $60 \%$ of the men rely on their spouse as a source of social support, and both men and women rated their spouses as the most helpful source of support during infertility treatment [54]. However, given the stresses associated with IVF, partners may, at times, find it difficult to be wholly responsive and supportive to one another [50].

The experienced psychological stress may impact the outcome of the IVF process [19]. Studies indicate that the very process of infertility therapy may bring about psychological problems, which additionally hinder conception of a child, overlapping with the already existing, somatic causes of infertility. Among other psychological factors that are significant for the infertility therapy Podolska and Bidzan [30] outline the relations in the family of origin and procreation, the reaction of the couple to the diagnosis, and the possibilities of treatment, one's self-esteem or accepting themselves in their social male/female role. Also the impact of the experienced anxiety and depressive symptoms for the outcomes of IVF fertilization is indicated [55]. Research has also shown that the role of the perceived sense of control among patients undergoing IVF treatment could be important for the success of the procedure [56].

\section{CONCLUSIONS}

The value add of psychology. In the past few decades, the success rates of IVF have significantly improved. Pregnancy statistics have increased with pregnancy efficacy rates in young patients of IVF averaging $30-40 \%$ per cycle, while among women over the age of 41 years, it has dropped to a few percent $[57,58,59]$. There is also a significant decrease in the multiple birth rate [60].

Undoubtedly, the increases in conception rates related to infertility therapy through IVF treatment indicates it is important to explore the factors related to the effective coping with the IVF treatment process, and to find the best possible way of helping couples to get through the procedure. The authors would particularly like to draw attention to the significance of the social support aspect of couples participating in the in vitro procedure.

Firstly, it is agreed that infertility is a serious psychological issue and that couples unable to conceive naturally look for solutions to assist them in the infertility issue. Thanks to its effectiveness, the IVF method is one of the most common methods of assisted reproduction. Secondly, there is consistent evidence that IVF is a very stressful experience that affects the functioning of individuals, and as a couple, and even 
the relationship with the child conceived through IVF. Not only does the IVF process affect a couple's relationship, but also the functioning of each member of the family. Finally, the study indicates that partners going through IVF may not have enough support from their closest social environments. It is argued that these unsupportive social interactions affect the well-being of couples and can hinder conception, and therefore are among the reasons for attrition from IVF, the most effective assisted reproduction method [61]. Fortunately, psychological interventions, especially those emphasizing stress management and coping-skills training, have been shown to have beneficial effects for infertility patients [62].

The authors indicate that there is a need to conduct systematic studies on the effect of supportive social interactions for the functioning of couples undergoing IVF. Infertility is a medical and serious psychological issue. It affects couples and is a source of self-reported stress, and it can be assumed that it also affects other areas of the life of a couple.

The role of psycho-education for couples undergoing IVF, and psychologists, therapists and medical personnel engaged in the issue of IVF treatment, may also be important and fruitful in future opportunities. Information related to the psychological health of IVF couples will also add value to the medical process undertaken with IVF, and may offer increases in the efficacy of the IVF treatment.

\section{REFERENCES}

1. Wdowiak A, Wdowiak A, Moroz E, Bojar I. Comparison of selected sperm parameters between 6,278 males in Poland and Ukraine. Ann Agric Environ Med. 2016; 23(1): 174-81.

2. Szkodziak P, Wozniak S, Czuczwar P, Wozniakowska E, Milart P, Mroczkowski A, Paszkowski T. Infertility in the light of new scientific reports - focus on male factor. Ann Agric Environ Med. 2016; 23(2): 227-30.

3. Malina A. Sex differences among young adults in the effectiveness of coping with the implementation of developmental tasks. In: Liberska $\mathrm{H}$, Malina A, Suwalska-Barancewicz D, eds. The functioning of contemporary young people in a changing world. Warszawa: Difin. 2012; 293-312.

4. Serdyńska M, Pawelczyk L, Jędrzejczak P. Infertility. In: Słomko Z, ed. Ginekology. Warszawa: Wydawnictwo Lekarskie PZWL. 2008; 465-555.

5. Eugster A, Vingerhoets AJJM. Psychological aspects of in vitro fertilization. A review. Soc Sci Med. 1999; 48: 575-589.

6. Bresnick E, Taymor M. The Role of Counseling in Infertility. Fertil Steril. 1979; 2: 154-156.

7. Berghius JP, Stanton AL. Adjustment to dyadic stressors: a longitudinal study of coping and depressive symptoms in infertile couples over an insemination attempt. J Consult Clin Psychol. 2002; 70, 433-438.

8. Monga M, Alexandrescu R, Katz S, Stein M, Ganiats T. Impact of Infertility in Quality of Life. Marital Adjustment and Sexual Function. Urology. 2014, 63, 126-130.

9. Freeman EW, Boxer AW, Rickels K, Tureck R, Mastroianni L Jr. Psychological Evaluation and Support in a Program of In Vitro Fertilization and Embryo Transfer. Fertil Steril 1985; 4: 48-53.

10. Szamatowicz M. Infertility. In: Bręborowicz GB, ed. Obstetrics and Gynaecology. Warszawa: Wydawnictwo lekarskie PZWL. 2007; 737756.

11. Mains L, Zimmerman M, Blaine J, Stegmann B, Sparks A, Ansley T, et al. Achievement test performance in children conceived by IVF. Hum Reprod 2010; 25: 2605-2611.

12. Visser A Ph, Haan G, Haan G, Wouters I. Psychosocial aspects of in vitro fertilization. J Psychosom Obstet Gynaecol 1994; 15: 1: 35-43.

13. Stewart DE, Robinson GE. Infertility by Choince or by Nature. Canadian Journal of Psychology 1989; 9: 866-871.

14. Lukse MP, Vacc NA. Grief. Depression and Coping in Women Undergoing Infertility Treatment. Obstet Gynecol 1999; 2: 245-251.
15. Newton CR, Sherrard W, Glavac I. The Fertility Problem Inventory: Measuring Perceived Infertility Related Stress. Fertil Steril 1999; 1: 54-62.

16. Csemiczky G, Landgren BM, Collins A. The influence of stress and state anxiety on outcome of IVF-treatment: Psychological and endocrinological assessment of Swedish women entering IVFtreatment. Acta Obstet Gynecol Scand 2000; 79: 113-118.

17. Pasch LA, Dunkel-Schetter C, Christensen A. Differences Between Husbands'and Wives' Approach to Infertility Affect Marital Communication and Adjustment. Fertil Steril 2002; 6: 1241-1247.

18. Glover L, Gannon K, Abel PD. Eighteen-month follow-up of male subfertility clinic attenders: a comparison between men whose partner subsequently became pregnant with those with continuing subfertility. Journal of Reproductive and Infant Psychology 1999; 17: 83-87.

19. Slade P, Emery J, Lieberman BA. A prospective, longitudinal study of emotions and relationship in in-vitro fertilization treatment. Hum Reprod 1997; 12, 1: 183-190.

20. Makara-Studzińska M. Morylowska-Topolska J. Wdowiak A. Bakalczuk G. Bakalczuk S. Anxiety and depression in women cured due to infertility. Prz Menopauz 2010; 9(6): 414-418.

21. Greil A. Infertility and psychological distress: A critical review of the literature. Soc Sci Med 1997; Vol. 45, Issue 11: 1679-1704.

22. Wright J, Bissonnette F, Duchesne C, Benoit J, Sabourin S, Girard Y. Psychological distress and infertility: men and women respond differently. Fertil Steril 1991; 55: 100-108.

23. Conrad R, Schilling G, Haidl G, Geiser F, Imbierowicz K, Liedtke R, et al. Relationships between personality traits, seminal parameters and hormones in male infertility. Andrologia 2002; 34(5): 317-24.

24. Bielawska-Batorowicz E. Psychological aspects of procreation. Katowice: Wydawnictwo Śląsk; 2006.

25. Whiteford L, Gonzales L. Stigma: The Hidden Burden of Infertility. Soc Sci Med 1995; 1: 27-36.

26. Abbey A. Adjusting to infertility. In: Harvey JD, Miller ED, eds. Loss and Trauma: General and Close Relationship Perspectives. Ann Arbour, MI: Edwards Brothers; 2000: 331-344.

27. Bielawska-Batorowicz E. Psychological aspects of diagnosis and treatment infertility. Ginekol Pol 1990; 12: 629-633.

28. Jordan C, Revenson TA. Gender differences in coping with infertility: A meta-analysis. J Behav Med1999; 22: 341-358.

29. Gana K, Jakubowska S. Relationship between infertility-related stress and emotional distress and marital satisfaction. J Health Psychol. 2014 pii: 1359105314544990.

30. Podolska M, Bidzan M. Niepłodność jako problem psychologiczny. Ginekol Pol 2011; 82: 44-49.

31. Larsen U. Primary and Secondary Infertility in Sub-Saharan Africa. Int J Epidemiol 2000; 29: 285-291.

32. Łepecka-Klusek C. Pozycja kobiety w małżeństwie bezdzietnym. Ginekol Pol 1997; 68: 204-208.

33. Kainz K. The Role of the Psychologist in the Evaluation and Treatment of Infertility. Women's Health Issues 2001; 6: 481-485.

34. Bączkowski T, Ciepiela P, Jaroszewicz A, Antonowicz A, SzołomickaKurzawa P, Kurzawa R. Rating sexual life of patients with infertility undergoing medically assisted reproduction. Family Medicine \& Primary Care Review 2007; 9/3: 375-377.

35. Edelmann RJ, Connolly KJ. Gender differences in response to infertility and infertility investigations: Real or illusory. British Journal of Health Psychology 2000; Vol. 5, Issue 4: 365-375.

36. Ardenti R, Campari C, Agazzi L, La Sala GB. Anxiety and perceptive functioning of infertile women during in-vitro fertilization: Exploratory survey of an Italian sample. Hum Reprod 1999; 14: 3126-3132.

37. Bringhenti F, Martinelli F, Ardenti R, La Sala GB. Psychological adjustment of infertile women entering IVF treatment: differentiating aspects and influencing factors. Acta Obstet Gynecol Scand 1997; 76(5): 431-7.

38. Huppelschoten AG, vanDongen AJCM, Verhaak CM, Smeenk JMJ, Kremer JAM, Nelen WLDM. Differences in quality of life and emotional status between infertile women and their partners. Hum Reprod 2013; 28(8): 2168-2176.

39. Salvatore P, Gariboldi S, Offidani A, Coppola F, Amore M, Maggini C. Psychopathology, personality, and marital relationship in patients undergoing in vitro fertilization procedures. Fertil Steril 2001; 75: 1119-1125.

40. Vikström J, Josefsson A, Bladh M, Sydsjö G. Mental health in women 20-23 years after IVF treatment: a Swedish cross-sectional study. Obstet gynaecol 2015; Vol 5, Issue 10: 1-8.

41. Pasch LA, Gregorich SE, Katz PK, Millstein SG, Nachtigall RD, Bleil $\mathrm{ME}$, et al. Psychological distress and in vitro fertilization outcome. Fertil steril 2012; 98(2): 459-464. 
42. Hjelmstedt A, Widström AM, Wramsby H, Collins A. Emotional adaptation following successful in vitro fertilization. Fertil Steril 2004; 81(5): 1254-64.

43. Filipowicz A. In vitro artificial fertilization - biomedical dilemmas of reproductive medicine. Pediatria Polska 2009; 84: 274-287.

44. Grzechocińska B. The fate of pregnancies achieved through assisted reproduction. Perinatologia, Neonatologia i Ginekologia 2010; 3: $132-135$.

45. Hammarberg K, Astbury J, Baker HWG. Women's experience of IVF: A follow-up study. Hum Reprod 2001; 16: 374-383.

46. Hahn Ch-S, DiPietro AJ. In Vitro Fertilization and the Family: Quality of Parenting, Family Functioning, and Child Psychosocial Adjustment. Dev Psychol 2001; 37: 37-48.

47. MacCallum F, Golombok S, Brinsden P. Parenting and child development in families with a child conceived through embryo donation. J Fam Psychol 2007; 21(2): 278-87.

48. McMahon CA, Gibson F, Leslie G, Cohen J, Tennant Ch. Parents of 5-year-old in vitro fertilization children: psychological adjustment, parenting stress, and the influence of subsequent in vitro fertilization treatment. Journal of Family Psychology 2003; 17(3): 361-369.

49. Makara-Studzińska M. Morylowska-Topolska J. Wdowiak A. Acceptance of diagnostic and therapeutic methods by married couples treated due to infertility. J Pre-Clin Clin Res 2010; 4(2): 141-144.

50. Abbey F, Andrews M, Hallmant L. Infertility and subjective well-being: The mediating roles of self-esteem, internal control and interpersonal conflict. J Marriage Fam 1992; 54(2): 408-417.

51. Mindes E, Ingram J, Kliewer W, James C. Longitudinal Analyses of the Relationship Between Unsupportive Social Interactions and Psychological Adjustments Among Women with Fertility Problems. Soc Sci Med 2003; 10: 2165-2180.

52. Amir M, Horesh N, Lin-Stein T. Infertility and adjustment in women: The effects of attachment style and social support. Journal of Clinical Psychology in Medical Settings 1999; 6: 463-479.
53. Malina A. Błaszkiewicz A. Owczarz U. Psychosocial aspects of infertility and its treatment. Ginekologia Polska 2016; 87, 7: 527-531.

54. Boivin J, Andersson L, Skoog-Svanberg A, Hjelmstedet A, Collins A, Bergh T. Psychological reactions during in-vitro fertilization similar response pattern in husband and wives. Hum Reprod 1998; 13: 32623267.

55. Zaig I, Azem F, Schreiber S, Gottlieb-Litvin Y, Meiboom H, Bloch $\mathrm{M}$. Women's psychological profile and psychiatric diagnoses and the outcome of in vitro fertilization: is there an association? Archive's of Womens Mental Health 2012; 15: 353-359.

56. Matsubayashi H, Hosaka T, Izumi S, Suzuki T, Kondo A, Makino T. Increased depression and anxiety in infertile Japanese women resulting from lack of husband's support and feelings of stress. Gen Hosp Psychiatry 2004; 26: 398-404.

57. Daly I. Bewley S. Reproductive ageing and conflicting clocks: King Midas' touch. Reprod Biomed Online 2013;27(6):722-32.

58. Wdowiak A. Wdowiak A. Comparing antioxidant enzyme levels in follicular fluid in ICSI-treated patients. Gynecol Obstet Fertil 2015; Jul-Aug;43(7-8): 515-21.

59. Lukaszuk K. Jakiel G. Kuczynski W. Pukszta S. Liss J. Plociennik L. Lukaszuk A. Pastuszek E. Next generation sequencing for preimplantation genetic testing of blastocysts aneuploidies in women of different ages. Ann Agric Environ Med 2016;23(1): 163-6.

60. Wade JJ, MacLachlan V, Kovacs G. The success rate of IVF has significantly improved over the last decade. Aust N Z J Obstet Gynaecol 2015; 55(5): 473-476.

61. Domar A. Impact of psychological factors on dropout rates in insured infertility patients. Fertil Steril 2004; 81(2): 271-273.

62. Cousineau TM, Domar AD. Psychological impact of infertility. Best Practice \& Research Clinical Obstetrics \& Gynaecology 2007; 21(2): 293-308. 